\title{
ELECCIONES EN MÉXICO: ENTRE LA IMPOSICIÓN Y LA CONCIENCIA DE CAMBIO
}

Humberto Márquez Covarrubias

Unidad Académica en Estudios del Desarrollo, UAZ

\begin{abstract}
La noción de democracia propia del neoliberalismo otorga al ciudadano las potestades de sufragar por "representantes populares" y delegar en ellos la atribución de legislar, diseñar políticas y manejar recursos públicos. La política se asume como una función administrativa a cargo de expertos, tecnócratas, cabilderos, consultores y políticos profesionales imbuidos en el manejo "responsable" de la macroeconomía, los programas de ajuste y las condiciones favorables para la inversión corporativa. El proceso electoral representa una puesta en escena mediática donde el guión determina candidatos ganadores, simula debates, anuncia quién va a ganar, emite el fallo $y$, al final, denuesta a los actores que trasgreden el argumento. Empero, sectores sociales informados y críticos emergen como actores que ponen en tela de duda la gran simulación y abogan por una democracia verdadera.
\end{abstract}

\section{Democracia de élites}

$\mathrm{L}$ a esfera de la democracia liberal se constriñe, en México, al ámbito formal (el voto) y participativo (la representatividad). Una multiplicidad de componentes formales y participativos se suprimen o regatean (derechos constitucionales, división de poderes, estado de derecho, libertad de expresión y elecciones libres; referéndum, plebiscito, rendición de cuentas, iniciativa popular, revocación de mandato, contraloría social, presupuesto participativo, etcétera). La dimensión social de la democracia (equidad, justicia, bienestar y seguridad humana) se omiten por completo. La fórmula básica de la democracia a la mexicana se ubica en el umbral más bajo: la ciudadanía, al votar, delega el poder social en supuestos "representantes". Sin embargo, el sufragio efectivo ha sido puesto en duda merced a la persistencia de la inequidad y turbiedad electorales, en tanto que la clase política continúa hundiéndose en el pantano del desprestigio y la ilegitimidad.

La simbiosis entre la democracia minimalista (un voto que puede ser mercantilizado) y el modelo neoliberal (la primacía de intereses corporativos) propicia que la oferta electoral y los proyectos de gobierno aboguen por el fortalecimiento del poder de los monopolios y la concentración de la riqueza plutocrática, a costa del despojo, explotación y pobreza de la mayoría de la población. Ante el malestar e indignación, los gobernantes han implementado estrategias de "desarrollo incluyente" que concede paliativos a los extremadamente pobres, como el programa Oportunidades, a la vez que conforma una base social de electores entre la población susceptible, por ignorancia o necesidad, de vender su voto.

El sistema de partidos, imbuido en la pospolítica y la nueva gerencia pública, no representa a la ciudadanía, ni mucho menos a las clases sociales subalternas: cam- pesinos, obreros, desempleados y migrantes, o sectores vulnerables como jóvenes, adultos mayores, mujeres, niños e indígenas. Las derechas e izquierdas partidarias, salvo contadas excepciones, están pertrechadas en los intereses creados y respaldan el modelo neoliberal. En México, la peor expresión de la partidocracia mexicana está representada por la unción de intereses encabezada por el polo de derechas, el PRIAN y los partidos comparsa que funcionan como franquicias o negocios familiares (PVEM y Panal). A ellos se suma la telebancada, congresistas que son personeros oficiosos del duopolio televisivo.

En las elecciones federales de julio de 2012, los contendientes presidenciales del Partido Revolucionario Institucional (PRI), Partido Acción Nacional (PAN) y Partido Nueva Alianza (Panal), sintetizaron en el estribillo "las reformas que el país necesita", su pretensión de llevar hasta las últimas consecuencias el modelo excluyente, explotador y depredador, bajo la consigna de que son medidas necesarias y responsables. Existe un claro consenso entre las élites económicas y políticas, que incluye a las corporaciones multinacionales, gobiernos imperiales y poderes fácticos, para dar continuidad al proyecto económico orientado a concentrar poder, capital y riqueza. Sólo el Movimiento Progresista, integrado por el Partido de la Revolución Democrática (PRD), el Partido del Trabajo (PT) y Movimiento Ciudadano (MC), planteó, aunque con moderación, el cambio de modelo. Optar por el candidato "menos malo", es, al parecer, la oportunidad que depara la vía electoral. Empero, el fantasma del fraude electoral, de nueva cuenta, con el triunfo del priísta Enrique Peña Nieto, frustra la energía social del pueblo mexicano interesado en la democracia y el cambio socioeconómico. Más allá de un nuevo episodio de alternancia electoral, el resurgimiento del priato presagia la consecución y profundización del neoliberalismo en México. 


\section{Mecánica de un fraude intonso}

En julio de 2012, diversos mecanismos fueron implementados para, de nueva cuenta, impedir el ascenso de la izquierda electoral. La columna vertebral la compone el cónclave de 16 gobernadores priístas ${ }^{1}$ que, a la vieja usanza, ejerce un férreo control político en la mayor parte de la extensa geografía nacional. La movilización de recursos presupuestales y de programas gubernamentales para la compra y coacción del voto desencadenó una competencia entre las campañas que movilizaban recursos federales y estatales. En la resaca electoral, una multiplicidad de videos, audios y fotografías atestiguan el reparto de enceres domésticos, prendas de vestir, útiles escolares y despensas; acarreo de personas; distribución de tarjetas de débito, telefónicas y de prepago; pagos en efectivo (200, 500 o 1,000 pesos) para inducir el voto; bodegas atestadas de regalos y materiales de construcción. Sobre estas menudencias, se denunciado el uso recursos millonarios para canalizar grandes parcelas del voto popular. Al viejo estilo de repartir dádivas y baratijas entre los pobres, nuevos mecanismos hicieron su aparición, como los monederos electrónicos del Grupo Financiero Monex (700 millones de pesos, ${ }^{2}$ con la presunción de triangulación de recursos y lavado de dinero) y las tarjetas electrónicas de prepago de la cadena de tiendas departamentales Soriana. ${ }^{3}$ Se estima que el PRI gastó la escandalosa cifra de 4.6 mil millones de pesos en gastos de campaña, ${ }^{4} 4.2$ mil millones de pesos más de lo permitido. La coalición de izquierda calcula que se compraron 5 millones de votos. ${ }^{5}$ El monopolio de la comunicación - ejercido por Televisa y sus seguidores en medios electrónicos e impresos- orquestó una campaña propagandística para entronizar al candidato del PRI, quien era presentado como una mercancía lustrosa. En cambio, AMLO era considerado como una persona obsesionada con el poder, un político mesiánico. La reiterada manipulación de encuestas sobre la intención del voto pretendía generar la sensación colectiva de una definición anticipada a favor del candidato oficial: entre 15 y 30 puntos de una aparentemente insuperable ventaja, cuando la diferencia, según los datos oficiales, fue de apenas $6.6 \%$; entre otras, la encuesta GEA-ISA, difundida diariamente por Milenio en un afán mercadotécnico fuera de toda ética periodística. ${ }^{6} \mathrm{Al}$ juego mediático se suman, como es habitual, los intelectuales orgánicos, periodistas y académicos que pretenden encubrir la turbulencia electoral y asumir, como cosa juzgada, el supuesto triunfo del candidato oficial, y de paso denostar a los movimientos sociales que reclaman la apertura de los medios de comunicación y la legalidad y legitimidad del proceso electoral. No es descabellado suponer que los gastos excesivos de campaña, más allá de los topes legales, contenían una mezcla de recursos públicos y privados, entre ellos recursos provenientes del crimen organizado, que de este modo podrían ser lavados. ${ }^{7}$ El Instituto Federal
Electoral (IFE), cuya composición atiende a cuotas partidarias, en detrimento de su autonomía e independencia, ha sido acusado de actuar de manera omisa o tendenciosa ante las evidencias de inequidad, turbiedad y corrupción inmiscuidas en el proceso electoral, antes, durante y después de la celebración de los comicios. Como si nada pasara, los consejeros presidentes del $\mathrm{IFE}^{8} \mathrm{y}$ del Tribunal Federal Electoral (TRIFE), ${ }^{9}$ han pretendido adelantar juicios en detrimento de los alegatos de la oposición y los movimientos sociales, sin agotar los recursos de revisión.

La canasta de votos prístas incluye votos alienados y votos conscientes. Entre los primeros, podemos distinguir dos categorías: el voto nostálgico, una buena parte del "voto duro" del priísmo anhela un retorno al pasado encarnado por el viejo PRI, aquel que algunos sectores populares identifican con el "desarrollo estabilizador", sin tomar nota de que el PRI hoy en día representa un proyecto antipopular, el neoliberal; y el voto tóxico o chatarra, los medios de comunicación y la compra de votos generan una burbuja electoral que incentiva el sufragio de población desinformada y pobre. Los votos conscientes incluyen también dos categorías. En primer lugar, los votos de la estructura prísta, el partido funge como una aceitada maquinaria electoral que busca ensanchar los ámbitos de poder e influencia, ubicar a sus operadores políticos en puestos clave de decisión y reconstruir la plataforma de lanzamiento hacia la constelación electoral y la esfera de los negocios. En segundo lugar, los votos tecnocráticos, aunque numéricamente son muy pocos, los jefes políticos y burocráticos, los líderes empresariales y sindicales, y los líderes de opinión no sólo votan según su propio interés, sino que tienen el poder de inducir el voto entre sus bases sociales, empleados, agremiados y auditorios. La inducción del voto sigue varias rutas, entre ellas el "voto del miedo". Con todo, la canasta de los votos priístas no concede legitimidad al presidente electo bajo los mecanismos que la erigen, pese a que las instituciones electorales se apresten a otorgarle el reconocimiento de legalidad.

\section{Teledemocracia}

El sistema de propiedad de los medios de comunicación en México destaca por ser de los más concentrados y privatizados del mundo. En la televisión prevalece un duopolio (Televisa/TV Azteca) que domina más del $90 \%$ de la televisión abierta y un monopolio (Telmex) en telefonía y tecnologías de la información. Televisa posee el $65 \%$ de las frecuencias de televisión abierta, con 225 estaciones repetidoras de sus cadenas nacionales, acapara $68 \%$ de las audiencias y concentra $70 \%$ de la publicidad en medios electrónicos y $58 \%$ de la publicidad en todos los medios. ${ }^{10}$

Un país no puede llamarse democrático, así se constriña a la sola esfera electoral, como es el caso, cuando carece de medios de información confiables y honestos. En México prevalece un modelo comunicacional antidemocrático, 
domeñado por las corporaciones televisivas, cuyo poder de penetración en las audiencias les permite modelar y mercantilizar la conciencia colectiva de amplios sectores de la población. Para la mayoría de la población -entre 70 y $80 \%$, dependiendo de la encuesta- la televisión representa la principal fuente de información y entretenimiento.

El influjo televisivo es determinante para descifrar el grado de enajenación de amplias capaz de la población y la capacidad que tiene el sistema de poder, por esta vía, para orientar ciertas preferencias electorales. Televisa es la cara más visible del sistema de poder mediático: manipula, tergiversa y oculta información, y además confecciona un discurso que pretende pasar como opinión pública, en consonancia con la argumentación oficiosa. Abogar por la apertura de los medios de comunicación y por la habilitación de nuevos espacios públicos y comunitarios de información es una tarea democratizadora primordial.

\section{Despertar juvenil}

El candidato iletrado - dice leer telenovelas, no puede enunciar el título de un libro y confunde el nombre de los autores-, representante de la tecnocracia neoliberal priísta, fue impugnado abiertamente por jóvenes universitarios, que sin temor expresaron una crítica certera en contra de la pretensión autoritaria de los poderes fácticos de imponer a su candidato y, además, exigieron la apertura de los medios de comunicación y de la contienda electoral, incluso organizaron, sobrepasando el pasmo del IFE, un debate entre los candidatos, al cual no acudió el aludido.

Cuando la representación mediática, a la cual se había reducido la contienda electoral, estaba bajo control, en el ámbito educativo, público y privado, emerge un actor de primer orden, el movimiento \#YoSoy132, que trastocó la frivolidad y demagogia imperantes en las campañas electorales recientes y sembró la semilla de la conciencia social y el despertar ciudadano, frente al autoritarismo de los poderes fácticos, cuya representación simbólica se encarna en el duopolio televisivo. Este movimiento está en ciernes, y dado que potencialmente puede constituirse en un contrapoder, afronta múltiples amenazas, pues los poderes fácticos y las élites del sistema de poder se sienten cuestionados y desnudados. Pero su desafío es mayor: superar el desenlace de los comicios manchados por el fantasma del fraude electoral para convertirse en un movimiento de largo aliento, vinculado a otras organizaciones sociales comprometidas con el cambio social, pero resguardando su autonomía e independencia. No obstante, los movimientos sociales críticos, como el zapatismo, las víctimas de la "guerra calderonista", los electricistas despedidos, los estudiantes rechazados, los defraudados electorales, y demás, no pueden delegar en los jóvenes organizados las responsabilidades propias. El desafío mayor es, una vez más, configurar un agente social transformador.
Este movimiento \#YoSoy132 es claridoso: surge cuando la juventud afronta un futuro aciago, pues se corrobora que el acceso al sistema educativo se estrecha y el mercado laboral excluyente y precarizado cancela los mecanismos de ascenso social; además de que se verifica que las juventudes subsumidas en la pobreza están siendo criminalizadas. Los poderes establecidos tergiversan a la juventud, pues mientras que el espectro de partidos políticos sólo ofrece la tónica del conservadurismo, oportunismo y corrupción, la omnipresente televisión, desde hace décadas, implementa una estrategia comunicacional que perfila una juventud consumista, conformista y apolítica. En ese entorno contrastante emerge una juventud crítica, que, a su manera, rememora a la sesentayochera. Pero ahora con un talante semejante a los indignados de España, los Occupy Wall Street de Estados Unidos, los estudiantes de Chile y los Aganaktismenoi de Grecia.

\#YoSoyl32 tiene la peculiaridad de carecer de un liderazgo visible y de estar subordinado a un partido político o supeditado a un candidato presidencial. Destaca por su autonomía e independencia y porque toma decisiones de manera colectiva. En lugar de reivindicar problemáticas que aquejen directamente a los involucrados, como sucede con movimientos gremiales o coyunturales, sus reivindicaciones interpelan a la población entera. La propuesta programática del movimiento, difundida en sus manifiestos, se articula en

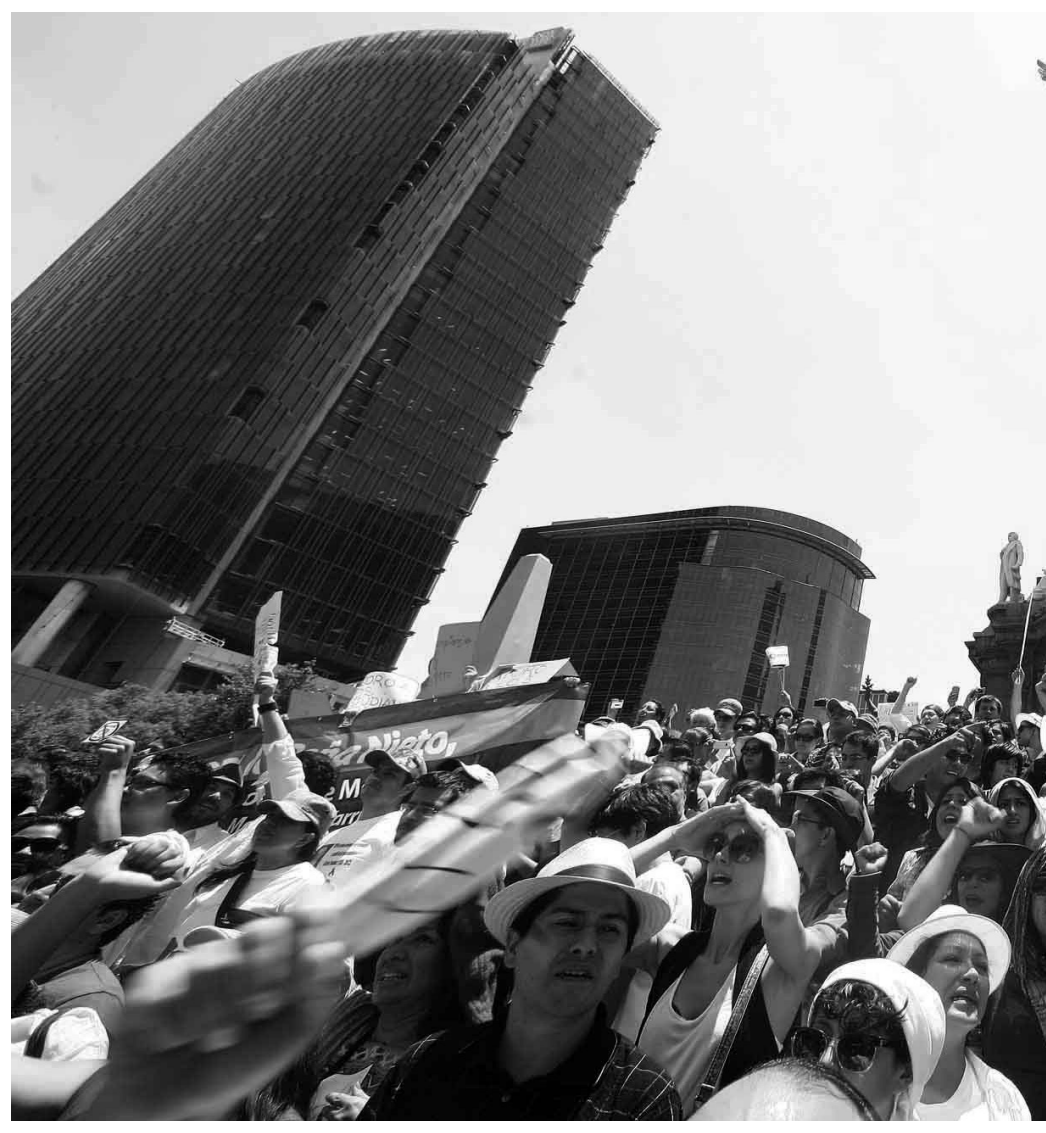


seis ejes: 1) "democratización y transformación de los medios de comunicación, información y difusión"; 2) "cambio en el modelo educativo, científico y tecnológico"; 3) "cambio en el modelo económico neoliberal"; 4) "cambio en el modelo de seguridad nacional y justicia"; 5) "transformación política y vinculación con movimiento sociales", y 6) "salud". "Además, el movimiento hace un llamado a los oprimidos para organizarse y articularse en una multiplicidad de luchas sociales engarzadas por una democracia auténtica. ${ }^{12}$

\section{Ética política: laberinto y salida}

La izquierda electoral representada por el PRD, el PT y $\mathrm{MC}$ se ha configurado, a su manera, como una maquinaria electoral, pero reproduciendo los vicios de las derechas: funge como agencia de colocación, cultiva el divisionismo interno, no estudia la realidad nacional y carece de un proyecto de transformación social. ${ }^{13}$

Los intelectuales y opinadores de derechas suelen dar lecciones y consejos a las izquierdas: que sea erijan como una izquierda moderna y moderada, entendiendo por ello que negocie y construya alianzas con la derecha. Y acusan a AMLO de sus derrotas electorales, por supuestos errores imperdonables, como el célebre plantón de la avenida Reforma, en la ciudad de México, para protestar contra el fraude electoral de 2006. Más allá de esas críticas

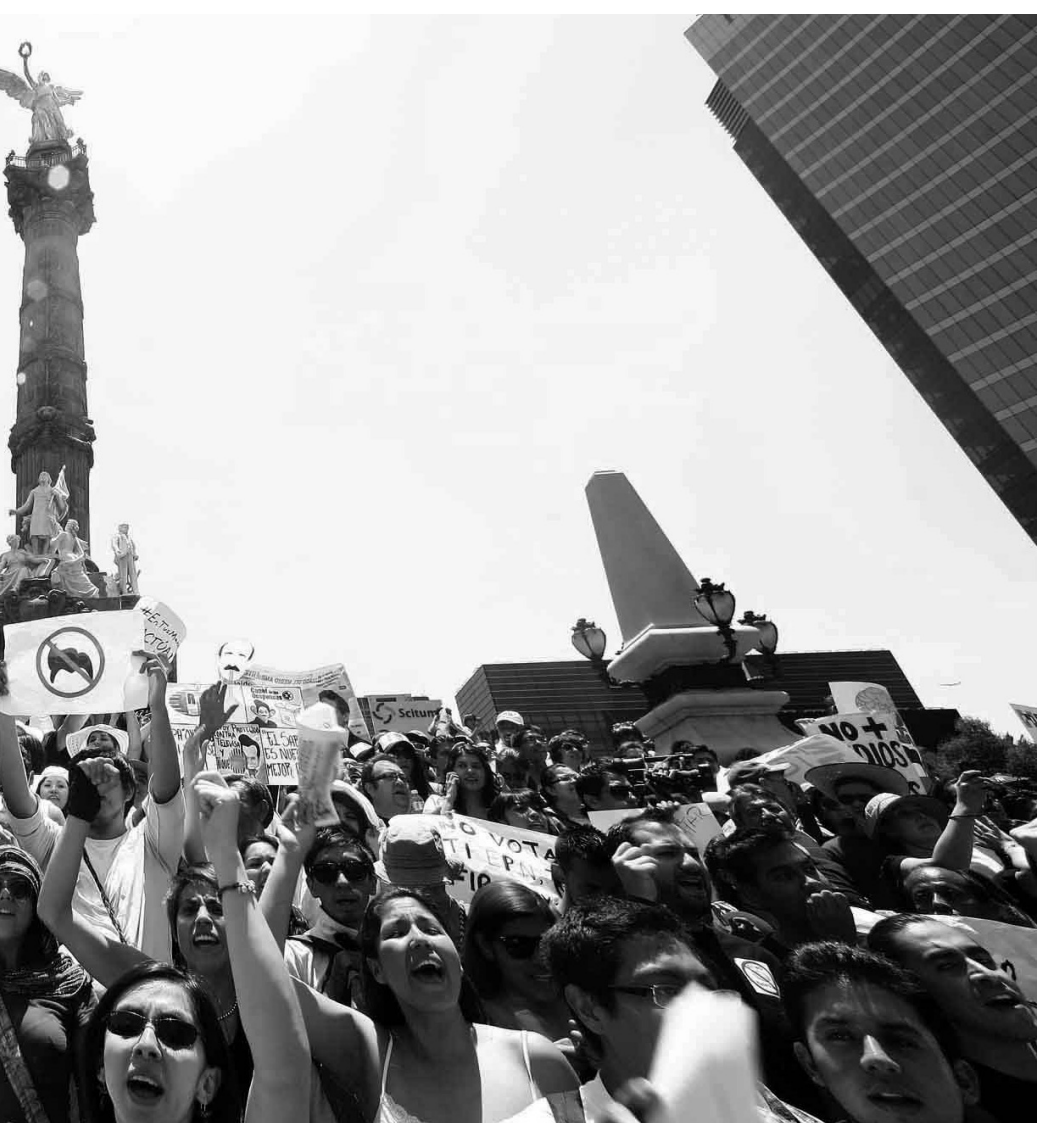

envenenadas, las izquierdas no pueden prescindir de la auténtica crítica y la autocrítica. $\mathrm{Al}$ respecto, las izquierdas electorales tienen varios y severos problemas: la carencia de un proyecto de nación, la corrupción y oportunismo de sus dirigentes y la crisis de representación. Sobre la falta de un proyecto de desarrollo, y pese a la publicación de Un proyecto alternativo de nación, ${ }^{14}$ La mafia que se adueñó de México... ${ }^{15}$ y Nuevo proyecto alternativo de nación, ${ }^{16}$ libros escritos con la intención de esbozar los lineamientos políticos de un proyecto de desarrollo alternativo al neoliberal, el frente de izquierdas no ha logrado articular un programa de gobierno alternativo, como lo demuestran las varias experiencias en estados y municipios bajo su conducción. En lugar de privilegiar los lineamientos estratégicos de un “cambio verdadero", el candidato de izquierdas divulgó un discurso de tono medio, ambiguo, que desvarió entre las abstracciones de una "República amorosa", la denuncia de "los que realmente mandan en el país" - en alusión a Televisa y al ex presidente Carlos Salinas-y la idea de reconciliación que pretendía tranquilizar a las asustadizas capas medias y atraer al empresariado nacionalista. En el olvido quedó la proclama que reza: "Por el bien de todos, primero los pobres". El discurso electoral estuvo plagado de ambigüedades, abstracciones y frases retóricas de ocasión. ${ }^{17}$ Sin contar los laberintos efectistas que prometían generar empleo y crecimiento con un programa de austeridad, sin ofrecer mucha claridad sobre la disponibilidad de recursos, pues dicho propósito no se vinculaba a una reforma hacendaria que suprimiera privilegios o evasiones fiscales de las grandes corporaciones y capitales especulativos.

Un núcleo duro de políticos corrompidos y aliados del neoliberalismo rodean al líder moral de las izquierdas, y además ocupan las posiciones de privilegio en las dirigencias partidarias y en los principales puestos de representación política. Por tanto, una tarea primordial de los partidos de izquierda debería de ser la depuración a fondo de las corruptelas y complicidades, dentro y fuera de los partidos; asentar la ética política, y construir un desarrollo posneoliberal. Ante la corrupción de los partidos de izquierda, sobre todo el PRD, AMLO y sus seguidores tuvieron la astucia de organizar el Movimiento de Regeneración Nacional (Morena), para suplir a los partidos oficiales y resguardarse en un incipiente partido-movimiento. Sin embargo, dicha organización ha estado centrada en preparar y movilizar votantes; no se ha interesado en procrear organizaciones de base, autónomas e independientes, que abran boquetes en el modelo neoliberal y actúen en el frente económico, social, ambiental y cultural. "Por el bien del partido, primero las urnas", pareciera ser la consigna.

En lugar de ejercer una representación concreta de las clases sociales despojadas, oprimidas y explotadas, el movimiento electoral de izquierdas está nucleado por la figura carismática de su líder, AMLO. En la práctica no existe un 
modelo de gestión gubernamental que sea representativo de las clases y sectores subalternos, identificado como de izquierda. Los programas de asistencia social del gobierno del Distrito Federal no puede concebirse, seriamente, como el basamento de un proyecto alternativo, aunque sí han sido efectivos para conformar una fiel base social electoral y apuntalar el liderazgo carismático de AMLO.

\section{Conclusión}

Para mantener a buen resguardo al modelo neoliberal y obstruir el triunfo de las izquierdas, el fantasma del fraude ha convulsionado al sistema electoral en los comicios federales de 1988, 2006 y 2012. La derecha gobernante no pretende ceder ni siquiera en el capítulo de la democracia electoral, pese a que la izquierda mexicana no es ni revolucionaria ni democrática ni socialista, y sólo dispone de un tibio programa que apenas pretende conferirle un "rostro humano" al neoliberalismo.

La alternancia electoral de 2000 significó sólo un recambio entre las filas de las derechas partidarias, que además de permitir el ascenso del PAN en la cúspide del poder político, y la remoción temporal del PRI, consolidó los cuadros tecnocráticos en las altas esferas de la burocracia política e intentó legitimar el proceso de neoliberalización. Con una nueva fachada partidaria resultó más fácil profundizar el modelo y atacar frontalmente los últimos resquicios del desvencijado modelo nacional-populista.

El proceso electoral, como mecanismo pacífico para promover cambios estructurales a la altura de las necesidades sociales, no parece ser la única salida. Pues reduce al ciudadano a su mínima expresión: un votante que delega en la clase política las decisiones cruciales. Resulta de mayor valía promover la organización social, no para movilizar ejércitos de votantes, sino para construir colectivamente alternativas de desarrollo basada en el bien común, el desarrollo humano, la democracia y la justicia social. Ya no es suficiente esperar a que desde arriba, como caídos del cielo, goteen los cambios necesarios.

Un "cambio verdadero" no puede reducirse a un eslogan de campaña o a la pretensión de materializar la alternancia electoral para permitir, por fin, el arribo al poder de una coalición de izquierdas, sino la gestación de cambios estructurales, políticos e institucionales con el respaldo de una fuerza social activa y consciente. $Y$ en este camino, la izquierda mexicano no ha definido su estrategia.

Referencias

${ }^{1}$ Villamil, Jenaro (21 de junio de 2012), "Sí hubo reunión de gobernadores priístas, confirma Eruviel”, Proceso, http:// www.proceso.com.mx/?p=311714

${ }^{2}$ Herrera, Claudia (26 de junio de 2012), "El priísta maneja $\$ 700$ millones en una estructura financiera ilegal, acusa AN, La
Jornada, p. 12, en: http://www.jornada.unam.mx/2012/06/26/ politica/012n2pol.

${ }^{3}$ Villamil, Jenaro (3 de julio de 2012), “El 'Sorianagate', fraude al voto", Proceso, en http://www.proceso.com.mx/?p=313139.

${ }^{4}$ Muñoz, Alma y Roberto Garduño (13 de julio de 2012), "Llamado al respaldo ciudadano", La Jornada, en http://www. jornada.unam.mx/2012/07/13/politica/007nlpol.

${ }^{5}$ Vergara, Rosalía (9 de julio de 2012), "AMLO: el PRI compró 5 millones de votos; transparentaré la elección”, Proceso, en http://www.proceso.com.mx/?p=313617.

${ }^{6}$ Gómez, Ciro (3 de julio de 2012), "Falló la encuesta MilenioGEA/ISA", Milenio, en http://www.milenio.com/cdb/doc/ impreso/9152111?quicktabs_1=1.

${ }^{7}$ Cervantes, Jesusa y José Gil Olmos (28 de julio de 2012), “Compra masiva de votos, una operación trasatlántica”, Proceso, en http://www.proceso.com.mx/?p=315369.

${ }^{8}$ Urrutia, Alonso (20 de julio de 2012), "Excesos y omisiones del IFE en su informe al TEPJF: Pablo Gómez”, La Jornada, en http://www.jornada.unam.mx/2012/07/20/ politica/007nlpol. Es escandaloso el enorme gasto de la alta burocracia mexicana. El consejero presidente del IFE gana 4 millones 12 mil pesos anuales.

${ }^{9}$ Urrutia, Fabiola y Fabiola Martínez (1 de julio de 2012), “Habrá conflicto poselectoral y lo dirimirá el TEPJF: Luna Ramos", La Jornada, en http://www.jornada.unam.mx/2012/07/01/ politica/003nlpol.

${ }^{10}$ Villamil, Jenaro (julio de 2009), "Concentración mediática y lavado de cerebros en América Latina”, Sala de Prensa, año X, vol. 5, en http://www.saladeprensa.org/art853.htm.

${ }^{11}$ Movimiento \#YoSoy132 (s.f.), "Manifiesto del \#YoSoy132 al pueblo de México”, en http://www.yosoy132media.org/ category/oficial/comunicados-oficiales/.

${ }^{12}$ El manifiesto del movimiento puede verse en: http://www.youtube.com/watch?v=igxPudJF6nU\&feature=player_embedded.

${ }^{13}$ No obstante, pese a que reparó durante seis años la campaña electoral, no logró cubrir la totalidad de las casillas ni documentar con prontitud y contundencia el cúmulo de infracciones, en buena medida ha dependiendo de los reportes ciudadanos, en especial de los jóvenes, pero los partidos resultan inoperantes.

${ }^{14}$ López Obrador, Andrés (2004), Un proyecto alternativo de nación, México, Grijalbo.

${ }^{15}$ López Obrador, Andrés (2010), La mafia que se adueñó de México... y el 2012, México, Grijalbo.

${ }^{16}$ Ramírez, Jesús (coord.) (2011), Nuevo proyecto de nación. Por el renacimiento de México, México, Grijalbo.

${ }^{17}$ Es sintomático el hecho de que AMLO marcará un tibio deslinde del Nuevo proyecto de nación en un foro empresarial de Cámara Nacional de la Industria de la Transformación (Canacintra), para eludir las criticas de los empresarios, al confesar que él sólo había escrito la introducción. O, que en otro foro empresarial haya manifestado su disposición de mantener el modelo macroeconómico. 